\title{
Real-Time Monitoring of Streptococcus mutans Biofilm Formation Using a Quartz Crystal Microbalance
}

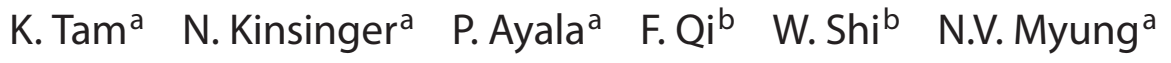 \\ a Department of Chemical and Environmental Engineering, University of California-Riverside, Riverside, Calif., and \\ ${ }^{b}$ Department of Oral Biology and Medicine, UCLA School of Dentistry, Los Angeles, Calif., USA
}

\section{Key Words}

In situ $\cdot$ Mutants $\cdot$ Quartz crystal microbalance $\cdot$ Real-time $\cdot$

Streptococcus mutans

\begin{abstract}
The ability of Streptococcus mutans, a well-known etiological agent in dental caries, to attach and form a biofilm is an important key to its virulence. The effects of various environmental factors (i.e. sucrose concentration, flow rate and temperature as well as genetic manipulations) on the capability of S. mutans (UA 140) to attach, form and detach were monitored in situ using quartz crystal microbalance. The biofilm growth rate was much slower than that of planktonic growth. Greater availability of sucrose contributed to biofilms with less lag time, lower doubling times and earlier detachment. Flow rate experiments showed that as the shear stress was reduced, the maximum mass accumulated also decreased. However, the detachment process was independent of shear force, perhaps indicative of quorum sensing. Increasing the incubation temperature from 37 to $40^{\circ} \mathrm{C}$ extended the lag period and inhibited the ability of the biofilm to attach readily. Absence of either the $c i a H$, luxS, gtfB or gtfC genes also greatly affected the ability of the $S$. mutans to adhere to a surface in comparison to the wild type. Quartz crystal microbalance results indicate that the gtfC gene possibly has a
\end{abstract}

greater contribution to biofilm attachment than the gtfB gene, that the presence of the luxS gene is critical for attachment and that the $\mathrm{CiaH}$ gene primarily affects the initial reversible attachment of the biofilm.

Copyright $\odot 2007$ S. Karger AG, Basel

Dental plaque is a microbial community which exists as a biofilm adherent to tooth surfaces with the help of adhesins and a polysaccharide matrix. More than $500 \mathrm{mi}-$ crobial species exist in dental plaque [Paster et al., 2001], including etiological agents of dental caries. Mutans streptococci are commonly present in plaque samples from dental caries sites [Loesche, 1986; Marsh and Bradshaw, 1995; Socransky et al., 1998; Kolenbrander, 2000]. Plaque formation is a multistep process which includes initial formation on a clean tooth surface of a pellicle consisting mostly of salivary components. Then microbial colonizers attach to the tooth surface through specific interactions between the bacterial adhesins and the surface receptors [Ellen et al., 1985; Lamont and Jenkinson, 2000] or nonspecific binding through bacterial polysaccharides. These pioneer colonizers are mainly gram-positive streptococci and actinomyces [Pearce et al., 1995]. The plaque continues to expand and grow through multiplication of the attached bacteria, as well as any bacteria

\section{KARGER}

(C) 2007 S. Karger AG, Basel

Fax +41613061234

E-Mail karger@karger.ch

www.karger.com
Accessible online at:

www.karger.com/cre
Dr. N.V. Myung

Department of Chemical and Environmental Engineering

University of California, Bourns Hall

Riverside, CA 92521 (USA)

Tel. +1 951827 7710, Fax +1 951827 5696, E-Mail myung@engr.ucr.edu 
from the saliva that are entrapped in the biofilm matrix [Marsh and Bradshaw, 1995]. Biofilms provide protection to the microbial community by regulating or buffering the environment from outside disturbances. In the case of dental plaque, the bacteria resist complete removal through forces incurred by brushing, chewing and swallowing. The plaque also affects the diffusion of acids and macromolecules depending on the presence of glucan. The permeability of acids is enhanced in glucan-rich plaque [Dibdin and Shellis, 1988; van Houte et al., 1989; Hata and Mayanagi, 2003], thus aggravating the acid-induced demineralization of the tooth enamel, while glucan appears to retard the permeability of macromolecules [Thurnheer et al., 2003]. Furthermore, biofilm cells are more resistant to environmental stress and antimicrobial agent treatments. The behavior of Streptococcus mutans was the focus of this research because of its colonization ability and its ubiquity in caries.

The development of a biofilm follows a number of phases including the transport of the planktonic cell to a surface, reversible attachment, irreversible attachment, maturation and differentiation and finally detachment [Davies, 2002]. The attachment ability of S. mutans and other biofilm-related attributes are influenced by the genetics of the organism. Three $g t f$ genes, $g t f B, g t f C$ and $g t f D$ [Ooshima et al., 2001] and $f t f$ genes [Li and Burne, 2001] control the synthesis of glucans and fructans, which constitute the extracellular matrix polysaccharides of S. mutans. The abundance of glucans allows for larger biofilm structures to form. Mutacin production by $S$. $m u$ tans provides antimicrobial activity against other bacterial species, including other streptococci. Inactivation of the $c i a H$ gene abolished mutacin I production and also affected competence development, sucrose-dependent biofilm formation and stress tolerance capability [Qi et al., 2004]. The luxS gene is thought to control the synthesis of autoinducer-2, a cell signal. Gene deletion of luxS was found to affect biofilm formation [Merritt et al.,

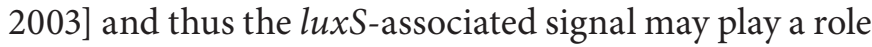
in biofilm formation. Thus far, these factors have not been investigated in real-time and in situ studies of S. mutans and mutants.

A few monitoring devices are capable of detecting the kinetics of deposits of materials in real-time and in situ, without differentiating between biotic and abiotic components [Flemming, 2003]. One is the quartz crystal microbalance (QCM), which detects the resonant frequency of an AT-cut quartz crystal located between 2 metal electrodes and uses piezoelectric sensors to measure weight at $0.1-1 \mathrm{ng} / \mathrm{cm}^{2}$. It was the aim of this study to apply the
QCM to studying the kinetics of $S$. mutans biofilm formation and maturation in real time, to obtain important information for understanding the virulence of $S$. $m u$ tans. The kinetic effects of sucrose concentration, flow rate and temperature, and the genetic effects of $S$. mutans on attachment were evaluated.

\section{The QCM}

QCM uses the concept of resonant frequency of an ATcut quartz crystal. As material deposits on the surface of the crystal, the frequency decreases according to the mass accreted. Direct correlations have been provided for rigid films [Sauerbrey, 1959]. However, for biofilms defined as viscoelastic [Klapper et al., 2002], further modifications are required to correlate the quartz crystal resonance frequency changes to the actual mass deposited. Equations to theoretically predict the response of viscoelastic media have been derived [White and Schrag, 1999]. Modification of the Sauerbrey equation to be applicable to liquid media and viscoelastic films (such as biofilms) has been the subject of ongoing research [Rodahl et al., 1997; Etchenique and Calvo, 1999]. These studies provided the 'proof-of-concept' for the present real-time studies on biofilm formation of $S$. mutans. Adapted to a flow cell, QCM can be used for on-line measurements of mass accumulation on the sensor surface over time for the in situ study of biofilm formation. Steps in microbial growth on the working electrode surface, including initial adsorption, reversible attachment, irreversible attachment and growth, and detachment could easily be measured to obtain the kinetics of an S. mutans biofilm cycle, since a monolayer of cells could be detected. Nivens et al. [1993] applied QCM to investigate the effects of pressure and temperature on Pseudomonas cepacia microbial biofilms, using a correlation between frequency shift and cell counts.

\section{Materials and Methods}

Bacterial Strain and Media

S. mutans strain UA 140 was grown anerobically on brain heart infusion (BHI) agar plates for 2 days at $37^{\circ} \mathrm{C}$ in a candle jar. $\mathrm{BHI}$ broth was inoculated with a single colony from the plates and incubated for $20 \mathrm{~h}$ at $37^{\circ} \mathrm{C}$. The overnight culture was diluted 1:100 into BHI broth with different sucrose concentrations that were tested before being injected into the QCM flow cell. Sucrose concentrations of $0,0.05,0.1,0.5$ and $1 \%(\mathrm{v} / \mathrm{v})$ were used for specific experiments, but the total carbon source was consistently $1 \%$ (v/v); glucose served to compensate. 


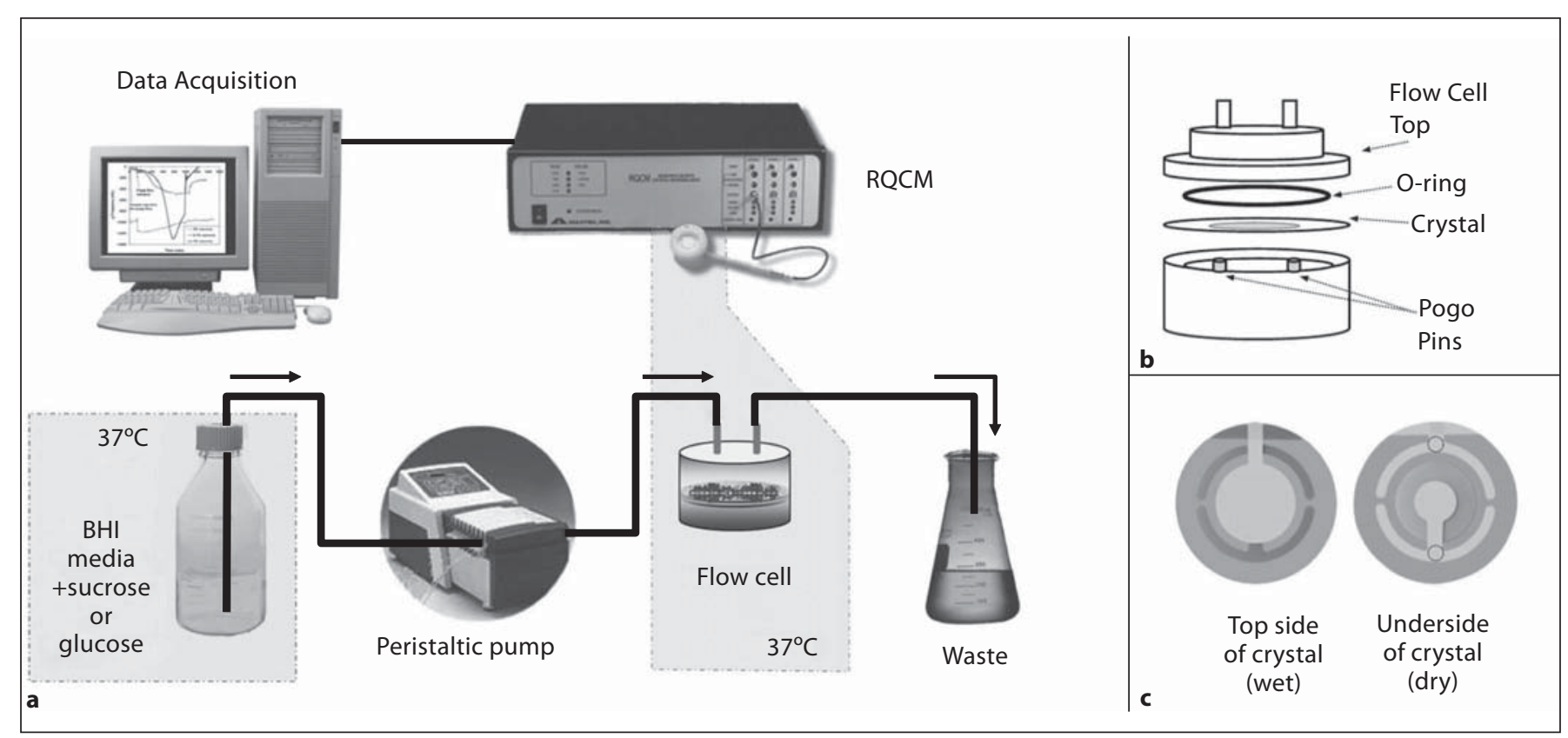

Fig. 1. a Experimental setup. b Flow cell configuration. c Quartz crystal surfaces where wetted side is exposed to the biofilm and the dry side gold electrode is in contact with the gold electrode pogo pins. Positions of contact indicated by dotted line circles on the underside of the crystal. RQCM = Research QCM.

\section{QCM Analysis}

The QCM system included the oscillator called a research QCM, a gold-plated 5-MHz AT-cut quartz crystal (polished for temperature experiments, unpolished for all other experiments) and a flow cell (Maxtek Inc., Santa Fe Springs, Calif., USA). The experimental setup is illustrated in fig. 1a. The flow cell configuration (fig. 1b) consisted of the flow cell top with inlet and outlet ports, a Kynar O-ring, the quartz crystal and gold pogo pins that are a part of the electronic circuit connecting to the gold electrodes etched on the quartz crystal (fig. 1c). The top surface of the quartz crystal exposed to the liquid was composed of approximately $50 \%$ gold and formed the electrode on the liquid side of the QCM system (fig. 1c). Active gold electrode areas (about 0.3419 $\mathrm{cm}^{2}$ ) on the top side and underside of the quartz crystal, which overlapped, were monitored for frequency change and hence mass attachment. Crystals were cleaned by immersion in 1 part $30 \%$ (v/v) hydrogen peroxide, 1 part $25 \%$ (v/v) ammonium hydroxide and 5 parts water at $75^{\circ} \mathrm{C}$ for $5 \mathrm{~min}$, rinsed with nanopure water (reverse osmosis water with activated carbon and additional 0.2 $\mu \mathrm{m}$ membrane treatment) and dried with a stream of nitrogen [Lu and Lewis, 1972]; the cleaning process was repeated twice. The clean crystals were then spin-coated with $0.15 \mathrm{ml}$ sterile saliva and spun until the surface was dry. Unstimulated saliva was obtained from 1 person (with consent) so that the saliva composition would not have much variability. The sterile saliva was prepared by a series of steps to denature and remove large proteins in the saliva including incubation at $60^{\circ} \mathrm{C}$ for $1 \mathrm{~h}$, centrifugation for $10 \mathrm{~min}$ at $14,000 \mathrm{~g}$, freezing at $-80^{\circ} \mathrm{C}$ for $2 \mathrm{~h}$, recentrifugation for $10 \mathrm{~min}$ at $14,000 \mathrm{~g}$ and filtering through a $0.2-\mu \mathrm{m}$ syringe filter. Aliquots of the sterile saliva were frozen in individual-use containers to avoid multiple freezing and thawing cycles. The crystal was spin-coated with the sterile saliva until dry, then placed under an ultraviolet light for $15 \mathrm{~min}$ to ensure sterility before being placed in the sterile flow cell of the QCM system.

\section{Experimental Procedure}

The quartz crystal and flow cell were first equilibrated in air at $37^{\circ} \mathrm{C}$ in an incubator for at least $2 \mathrm{~h}$. The manufacturer's literature indicated that temperature affected the shear mode oscillation of the quartz crystal as well as the density of the fluid. Frequency changes due to temperature can be magnified when the sensor crystal is exposed to liquids, so at least $30 \mathrm{~min}$ was allowed for equilibrium to be reached for accurate measurements. To initiate attachment of $S$. mutans, $0.1 \mathrm{ml}$ of a 1:100 diluted overnight culture (approximately $10^{6} \mathrm{cfu} / \mathrm{ml}$ ) was injected into the flow cell and a 2 -hour static culture growth period followed. Thereafter, a constant flow rate of sterile BHI sucrose solution, maintained at a set temperature using a water bath, was continuously delivered into the flow cell using a peristaltic pump (model 2055; Watson Marlow Ltd, Falmouth, UK). The flow cells were maintained at the prescribed temperature throughout the experimental period except for the brief period during inoculation and during attachment of the pump tubing to the flow cell. Data acquisition software (Maxtek) was used to record resonant frequency changes, estimated mass change (based on rigid films) and resistance of the crystal every minute as the biofilm developed on the surface of the quartz crystal. At the end of each experiment, residual fluid was pumped from the flow cell chamber, which has a volume capacity of about $0.1 \mathrm{ml}$. The QCM crystal was retrieved and both wet and dry weights of the biofilm were recorded using a model 
XS105 balance (Mettler Toledo, Columbus, Ohio, USA), with a readability of $0.1 \mathrm{mg}$ and an accuracy of $0.0004 \%$. Dry weights were obtained by drying the biofilm-laden crystals in an oven at $80^{\circ} \mathrm{C}$ for 2 days. All experiments were performed in triplicate.

Correlation of QCM Mass Readings with Actual Biofilm Mass Sauerbrey's equation was modified to obtain the actual biofilm mass on the surface of the crystal. A series of biofilm formation experiments were performed, terminating 5, 10, 15, 20 and $24 \mathrm{~h}$ after an initial 2-hour static culture growth. At the end of each time interval, the fluid was pumped out and the wet mass of the crystal and surface contents were measured as above. Subtracting the mass of the dry saliva-coated quartz crystal, the measured wet mass of the surface contents, denoted the 'actual mass', was compared with the mass change calculated from the Maxtek data acquisition software, denoted the 'QCM mass', which was calculated from the frequency change. The actual mass included the liquid media in contact with the crystal surface, the biofilm attached to the quartz surface and any products of metabolism including extracellular polysaccharides (EPS). Time interval experiments provided a representative trend line for actual mass increase on the crystal surface for biofilm experiments using $1 \%$ $(\mathrm{v} / \mathrm{v})$ sucrose in BHI broth. These experiments were conducted at $37^{\circ} \mathrm{C}$, with a flow rate of $0.21 \mathrm{ml} / \mathrm{min}$, corresponding to the minimum unstimulated salivary flow.

\section{Effect of Sucrose Concentration on Biofilm Development}

S. mutans biofilms were grown in BHI broth with $0,0.05,0.1$, 0.5 and $1 \%(\mathrm{v} / \mathrm{v})$ sucrose, and mass accumulation was recorded over $24 \mathrm{~h}$ after the 2 -hour static culture period. Experiments were performed at $37^{\circ} \mathrm{C}$ and a flow rate of $0.21 \mathrm{ml} / \mathrm{min}$.

\section{Effect of Flow Rate on Biofilm Development}

Experiments with flow rates of 0.05 and $0.13 \mathrm{ml} / \mathrm{min}$ were performed for comparison with the flow rate of $0.21 \mathrm{ml} / \mathrm{min}$ to determine whether maximum mass and detachment were dependent on the shear stress on the biofilm. All experiments were performed using $\mathrm{BHI}$ broth with $1 \%(\mathrm{v} / \mathrm{v})$ sucrose concentration at a temperature of $37^{\circ} \mathrm{C}$. The flow rates tested were all in the laminar flow region $(\operatorname{Re}<4)$

Temperature Effect on Biofilm Development

QCM is affected by temperature [Nivens et al., 1993], so 1 set of experiments was performed at $40^{\circ} \mathrm{C}$ for investigating the effect of a small rise in temperature from $37^{\circ} \mathrm{C}$. BHI broth with $1 \%$ sucrose was used with a flow rate of $0.21 \mathrm{ml} / \mathrm{min}$.

\section{Genetic Effects}

A series of experiments using BHI solution with $1 \%$ sucrose, a flow rate of $0.21 \mathrm{ml} / \mathrm{min}$ and $37^{\circ} \mathrm{C}$ were conducted with mutants of $S$. mutans to obtain a better understanding of certain genes and their effects on biofilm attachment. Four mutants were tested, denoted by the gene deletion as $c i a H, \operatorname{luxS}, g t f B$ and $g t f C$. The ciaH and $l u x S$ mutants were described previously [Qi et al., 2004; Merritt et al., 2005]. The $g t f B$ and $g t f C$ mutants were generated by transferring the chromosomal DNA from previously constructed S. mutans strains UA130B and UA130C [Yamashita et al., 1993] into UA140.

\section{Results}

\section{Reproducibility}

In preliminary experiments, $S$. mutans bound to quartz crystals, which had been cleaned but not salivacoated, showed long lag phases. Coating the crystals with sterile saliva significantly improved attachment. For triplicate experiments the rates of mass increase were fairly reproducible, with standard deviations ranging between $2 \%$ and $26 \%$, which is not unusual for biological growth.

\section{Correlation of QCM Mass Readings to Actual Biofilm} Weight

In the time-interval experiments, a linear relationship was found between the actual wet mass $\left(M_{a c}\right)$ and the QCM mass $\left(M_{Q C M}\right)\left(\mu \mathrm{g} / \mathrm{cm}^{2}\right)$ :

$$
M_{a c t}=305.84 M_{Q C M}+593.18\left(r^{2}=0.94\right)
$$

Since performing this correlation for each set of experiments would be both labor- and time-intensive, and because of the good linearity obtained for the time interval experiments, it was assumed that the relationship between actual mass and QCM mass would be applicable for the other sucrose concentrations tested, if attachment occurred. An abbreviated method of determining the linear trend line from the initial and final actual wet masses and QCM masses was used. The initial actual wet mass was approximated as $785 \pm 16 \mu \mathrm{g} / \mathrm{cm}^{2}$, the wetted weight of the growth medium on the crystal surface from the control experiments with no microbial inoculation. At the close of the experiment, the final wet mass of the biofilm was obtained along with the final QCM mass. For example: if a QCM mass of $19.2 \mu \mathrm{g} / \mathrm{cm}^{2}$ was recorded and the corresponding actual wet mass on the crystal surface was $2,119 \mu \mathrm{g} / \mathrm{cm}^{2}$, the linear trend equation would be:

$$
M_{\text {act }}=69.48 M_{Q C M}+785
$$

This equation enabled monitoring of the true masses associated with attachment and growth of a viscoelastic biofilm directly from the QCM mass provided by the data acquisition software.

\section{Effect of Sucrose Concentration on Biofilm \\ Development}

As shown in figure 2, directly after inoculation, the wet actual mass (as translated from the QCM mass) would either increase or decrease during the 2-hour static culture period; this was attributed to the change in temperature, since inoculation was performed outside the $37^{\circ} \mathrm{C}$ incubation chamber. The mass readings leveled out dur- 
Fig. 2. Representative plots of actual wet mass (translated from QCM mass) accumulated over time at sucrose concentrations of $1,0.5,0.1,0.05$ and $0 \%(\mathrm{v} / \mathrm{v})$ in BHI medium at $37^{\circ} \mathrm{C}$ and a flow rate of $0.21 \mathrm{ml} /$ $\min$.

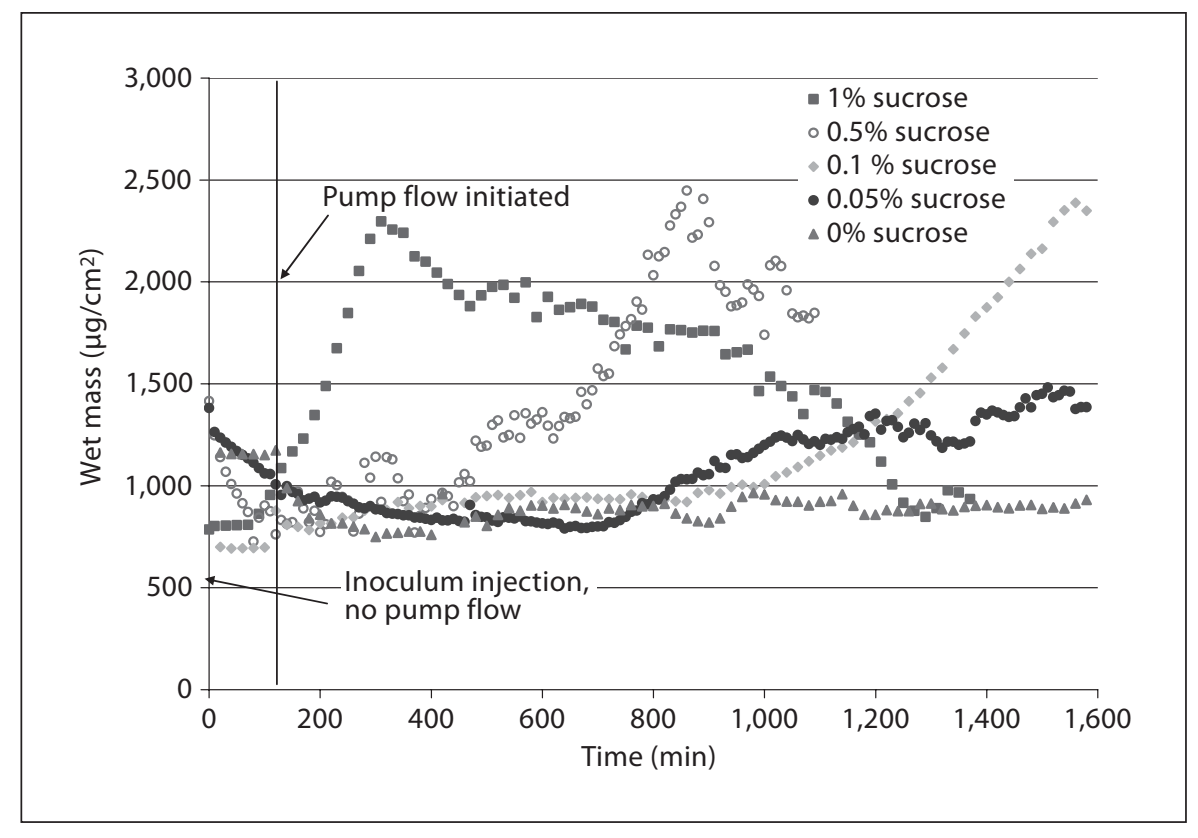

ing the 2-hour static culture period. In addition, the mass curves all decreased after the pump flow was started; this too was considered to be an artifact due to the momentary change in temperature associated with inoculation and pump attachment to the flow cell.

The biofilm growth curves resembled those of planktonic cultures: a lag period, followed by an exponential phase, stationary and death phases (fig. 2), but here the curves represent the net mass of adherent microbial growth (including metabolite production) and detachment of cells. Measurements of lag periods, biofilm doubling times, detachment times and maximum mass are shown in table 1 . In the absence of sucrose, with only $1 \%$ glucose, a weakly attached biofilm was produced, with a maximum wet mass less than half of the masses at more substantial sucrose concentrations $(0.1-1 \% \mathrm{v} / \mathrm{v})$. Long lag periods occurred at lower concentrations of sucrose $(0.05$ and $0.1 \%$ ), while at 0.5 and $1 \%$ sucrose biofilm doubling time was significantly decreased. In fact, an order of magnitude increase in sucrose concentration (0.1-1.0\%) resulted in a $70 \%$ decrease of the doubling time. Another interesting feature is that the maximum masses accumulated for the $1,0.5$ and $0.1 \%$ sucrose cases were all very similar. Thereafter, the mass would decrease, indicating a detachment process.

\section{Effect of Flow Rate on Biofilm Development}

Representative plots are shown in figure 3. In general, as the shear stress decreased, the maximum mass accu-
Table 1. Lag, growth, maximum biofilm wet mass and detachment periods of $S$. mutans in relation to sucrose concentration performed at $37^{\circ} \mathrm{C}$ and a flow rate of $0.21 \mathrm{ml} / \mathrm{min}$

\begin{tabular}{lcclc}
\hline $\begin{array}{l}\text { Sucrose concen- } \\
\text { tration }(\mathrm{v} / \mathrm{v}), \%\end{array}$ & $\begin{array}{l}\text { Lag time, } \\
\mathrm{min}\end{array}$ & $\begin{array}{l}\text { Doubling } \\
\text { time, min }\end{array}$ & $\begin{array}{l}\text { Max. wet } \\
\text { mass, } \mu \mathrm{g} / \mathrm{cm}^{2}\end{array}$ & $\begin{array}{l}\text { Detachment } \\
\text { time, min }\end{array}$ \\
\hline 1.0 & $0 \pm 0$ & $160.0 \pm 8$ & $2,306 \pm 184$ & $219 \pm 11$ \\
0.5 & $270 \pm 20$ & $234.7 \pm 30$ & $2,355 \pm 177$ & $781 \pm 39$ \\
0.1 & $709 \pm 57$ & $527.7 \pm 41$ & $2,395 \pm 196$ & $1,471 \pm 129$ \\
0.05 & $556 \pm 52$ & $556.0 \pm 47$ & $1,471 \pm 101$ & $1,428 \pm 228$ \\
0 & $279 \pm 153$ & N/A & $1,035 \pm 60$ & $313 \pm 127$ \\
\hline
\end{tabular}

Figures are means $\pm \operatorname{SD}(n=3)$. N/A $=$ Not applicable.

mulated also decreased. At $0.21,0.13$ and $0.05 \mathrm{ml} / \mathrm{min}$, the maximum masses achieved were 2,306 $\pm 184,2,080 \pm$ 148 and $1,741 \pm 112 \mu \mathrm{g} / \mathrm{cm}^{2}$, respectively. At each flow rate tested, a decrease in wet mass occurred, indicating detachment of the biofilm. Even at $0.05 \mathrm{ml} / \mathrm{min}$, with a lower shear rate, biofilm detachment was still detected at approximately $360 \mathrm{~min}$ (fig. 3). At 0.13 and $0.21 \mathrm{ml} / \mathrm{min}$, the wet mass readings showed fluctuations indicating a sequence of detachment and reattachment of the biofilm. This occurred at the lower flow rate but less extensively.

Temperature Effect on Biofilm Development

Representative wet mass plots at 37 and $40^{\circ} \mathrm{C}$ are shown in figure 4 . With an increase of $3^{\circ} \mathrm{C}$, growth was signifi- 
Fig. 3. Representative actual wet mass (translated from QCM mass) plots for flow rates of $0.05,0.13$ and $0.21 \mathrm{ml} / \mathrm{min}$ performed at $37^{\circ} \mathrm{C}$ and in $\mathrm{BHI}$ with $1 \%(\mathrm{v} / \mathrm{v})$ sucrose.

Fig. 4. Effect of temperature on actual wet mass (translated from QCM mass), with solutions of BHI and $1 \%(\mathrm{v} / \mathrm{v})$ sucrose at a flow rate of $0.21 \mathrm{ml} / \mathrm{min}$.
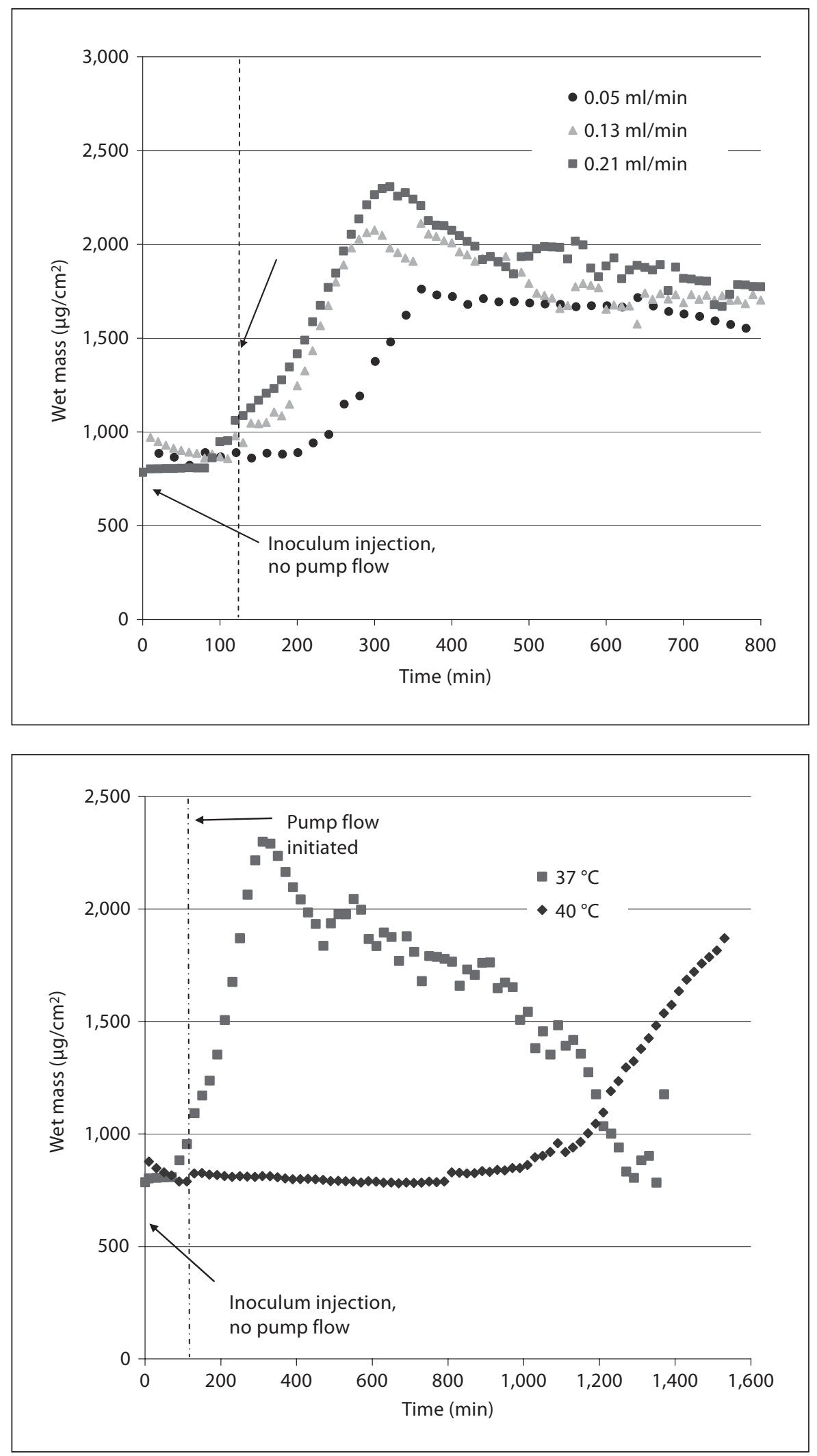
Fig. 5. Effects of wild type and mutant strains of $S$. mutans on QCM mass readings in experiments conducted with $\mathrm{BHI}$ media with $1 \%$ sucrose, at $37^{\circ} \mathrm{C}$ and at a flow rate of $0.21 \mathrm{ml} / \mathrm{min}$. a Comparison of $g t f B$ and $g t f C$ mutants to the wild type (wt) and control. b Comparison of ciaH and luxS to the wild type and control. Control experiment had no microbial inoculum.
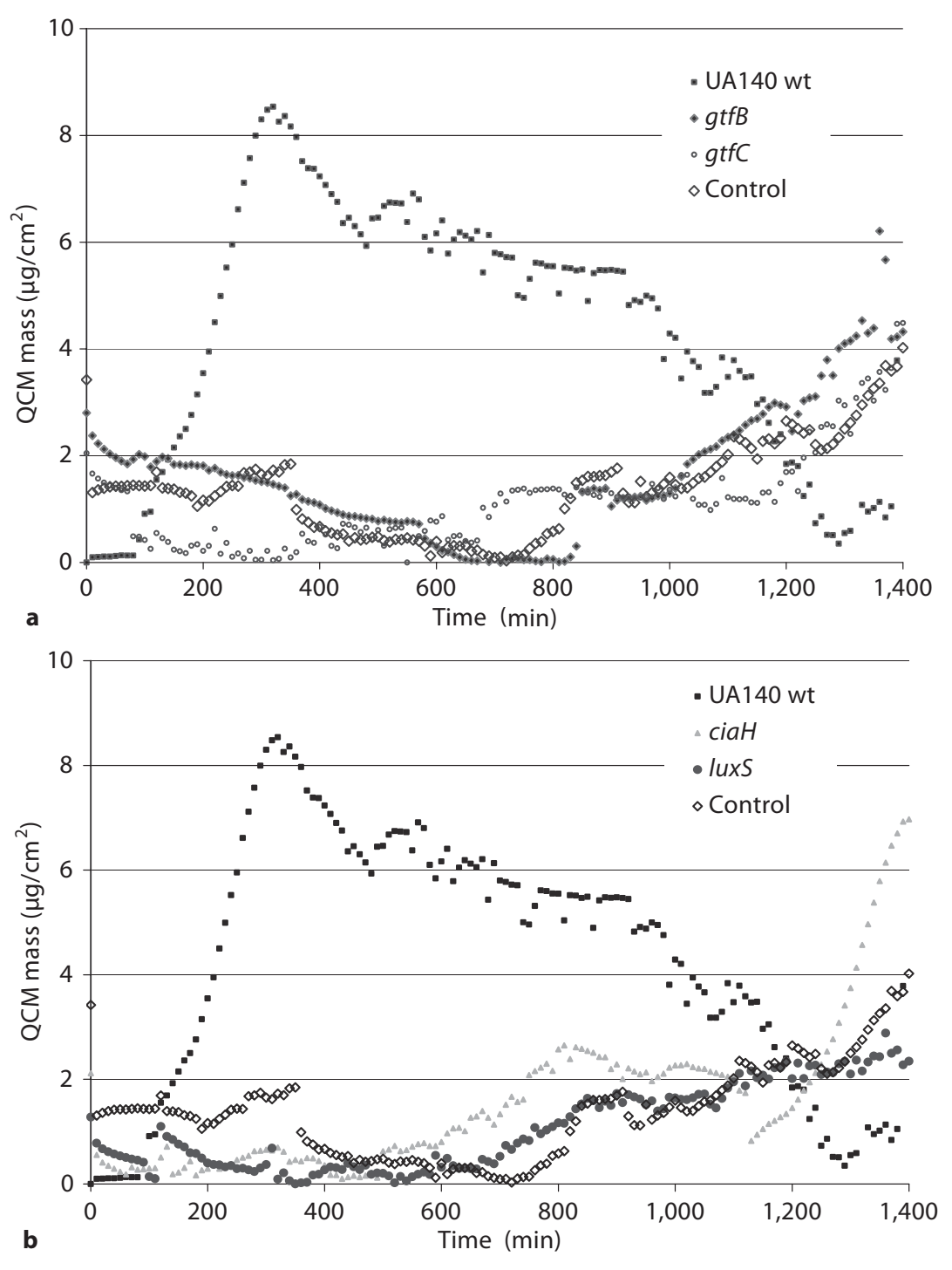

cantly slowed with a prolonged lag phase of $810 \pm 52 \mathrm{~min}$ after inoculation. The final mass achieved within $24 \mathrm{~h}$ at $40^{\circ} \mathrm{C}$ was approximately $19 \%$ less than at $37^{\circ} \mathrm{C}$. The doubling time at $40^{\circ} \mathrm{C}(529 \pm 27 \mathrm{~min})$ was significantly higher than that at $37^{\circ} \mathrm{C}(160 \pm 9 \mathrm{~min})$, so an increase of $3^{\circ} \mathrm{C}$ significantly slowed the overall biofilm growth.

\section{Genetic Effects}

Representative results are shown in figure 5 using the QCM mass instead of the actual wet mass. Figure 5a includes plots for the control (uninoculated), wild type and the mutants of $g t f B$ and $g t f C$. Figure $5 b$ compares the control and the wild type results with the mutants ciaH and luxS. Based on the QCM mass readings alone, it was expected that little biomaterial would be on the crystal surface for the mutants tested. However, when the flow cell was dismantled, a significant quantity of biomass was found, which easily fell from the crystal surface. As little attachment occurred onto the crystal surface (low QCM mass readings), this biomass was due to planktonic growth in the flow cell above the crystal.

The growth in biomass in the wild type and the mutants, as dry weight of the biomass and metabolites, are shown in table 2 , along with the water content of the biomass. The water contents were very similar $(81.8 \pm 3.2$ to $88.4 \pm 1.7 \%)$. With respect to the biomass dry weights, 
Table 2. Biomass dry weights and water contents of control, wild type and mutant biofilms

\begin{tabular}{lcc}
\hline Species & Dry weight, $\mu \mathrm{g} / \mathrm{cm}^{2}$ & Water, \% \\
\hline Control & $36.0 \pm 4.1$ & $95.4 \pm 0.5$ \\
UA140 wt & $352.6 \pm 38.3$ & $83.9 \pm 1.9$ \\
ciaH & $392.6 \pm 69.1$ & $84.2 \pm 0.3$ \\
luxS & $461.9 \pm 13.8$ & $83.0 \pm 0.5$ \\
gftB & $695.3 \pm 110.0$ & $81.8 \pm 3.2$ \\
gtfC & $299.0 \pm 13.8$ & $88.4 \pm 1.7$ \\
\hline
\end{tabular}

Figures are means $\pm \mathrm{SD}(\mathrm{n}=3) . \mathrm{wt}=$ Wild type.

$5-12 \%$ is attributable to the solutes of the $\mathrm{BHI} / 1 \%$ sucrose broth. The dry weight data demonstrated that the growth capability of $S$. mutans strains deficient in $c i a H$, luxS and $g t f B$ were not impaired but that of the $g t f C$-deficient strain was, albeit minimally when the standard deviations were considered. The biomass dry weights by the mutant strains increased in the order $c i a H, l u x S$ and $g t f B$ (table 2). The results in table 2 and figure 5 indicated that mutants deficient in $c i a H, \operatorname{luxS}, g t f B$ or $g t f C$ were capable of producing biomass (biofilm or planktonic) but were significantly compromised in the ability to attach, as reflected in the QCM mass. In fact, QCM traces of the luxS, $g t f B$ and $g t f C$ cases were similar to the baseline case of uninoculated control experiments. The $\mathrm{ciaH}$ mutant was the exception, with some attachment detected from 500 to $1,080 \mathrm{~min}$ into the experiment, followed by a significant detachment at approximately 1,120 min, followed by more significant attachment starting from 1,260 to 1,400 min. The initial attachment stages were greatly affected in comparison to the wild type.

\section{Discussion}

To monitor the biofilm development and growth of S. mutans, previous techniques have required sampling of the biofilm from the support medium by sonication or physical means for measuring cell count and viability [Lee et al., 1996], or dry weight measurement and chemical analysis [Hayacibara et al., 2003]. However, in situ methods such as electrochemical QCM and QCM, which have been used to investigate other micro-organisms such as mixed cultures from drinking water biofilms [Bressel et al., 2003] and P. cepacia [Nivens et al., 1993], would be beneficial. Bressel et al. [2003] applied electrochemical QCM to record frequency readings but used separate batch experiments with removable platinum electrodes for further molecular probe staining and viewing with confocal scanning laser microscopy for correlation with biofilm growth. In previous research we translated frequency results directly to mass using Sauerbrey's correlation [Kreth et al., 2004]. However, after further investigation, it was determined that the Sauerbrey relationship required modification to correctly represent the biofilm attached to the surface of the quartz crystal, as in the work of Nivens et al. [1993], and the method used in the present study provided a means to monitor the net biofilm growth in situ using the total mass which included the byproducts, viable and nonviable cells, and losses due to detachment or sloughing.

Quartz crystal surfaces were coated with salivary proteins to aid in the attachment of S. mutans onto the quartz crystal surface and to mimic the pellicle on a tooth surface. With the salivary components on the surface of the gold plated quartz crystal electrode, the effect of the different surface material was reduced or eliminated. Francis et al. [2000] found that some lower molecular weight proteins can be reduced by freeze-thawing, in particular for submandibular-sublingual saliva. However, for this research, pellicle was formed from sterile saliva samples which were consistent between all experiments and provided a basis for comparing the environmental parameters investigated.

It was expected that the greater the availability of sucrose, the greater the production of EPS would be and hence growth of thicker biofilms would be promoted. The data in table 1 confirmed such an increase up to $0.1 \%$ sucrose. The higher mass values, in comparison with that for an equivalent concentration of glucose, implied that in the presence of sucrose the biofilm had greater EPS content. The growth and survival of $S$. mutans are dependent on the formation of the EPS matrix, which is critical for consolidating the biofilm matrix and for buffering the community from antimicrobial agents and predation. The glucan content also facilitates the diffusion of nutrients to the deeper levels of the biofilm to maintain an environment suitable for their proliferation. Van Houte et al. [1989] detected a drop in the $\mathrm{pH}$ levels deeper into the $S$. mutans strain 1B-1600 grown in ToddHewitt broth supplemented with sucrose. It is clear that sucrose availability significantly affects biofilm formation by $S$. mutans UA140, low sucrose concentrations resulting in long lag periods and lower total mass attachment. Sucrose is the substrate for glucosyltransferases B and $\mathrm{C}$, which form water-insoluble glucans. These allow the bacteria to stick firmly onto the tooth surface and 
form a biofilm [Yamashita et al., 1993; Yoshida and Kuramitsu, 2002]. The availability of sucrose thus provides the means for development of a thicker biofilm matrix, which allowed the attainment of a critical maximum mass of about $2,350 \mu \mathrm{g} / \mathrm{cm}^{2}$ before detachment of the biofilm. It appeared that a minimum concentration of $0.1 \%$ sucrose was required to achieve the maximum mass within $24 \mathrm{~h}$ after pumping commenced. Similar shapes in the wet mass plots (fig. 2) were observed for the $0.1,0.5$ and $1 \%$ sucrose concentrations. For these 3 concentrations, the lower the concentration, the greater the lag period. As the sucrose concentration was reduced, the peak of the maximum wet mass shifted to the right, indicating that availability of sucrose was important in the development and accumulation of the biofilm matrix. This was further emphasized in the $0 \%$ sucrose case, where although the total carbon source was the same as the other concentrations tested, $0 \%$ sucrose runs did not have any significant attachment on the surface of the crystal.

The doubling times for S. mutans decreased from 556 to $160 \mathrm{~min}$ as the sucrose concentration increased from 0.05 to $1 \%$. At low concentrations of sucrose $(0.05$ and $0.1 \%)$, attachment was very weak and doubling times were similar. Although it was difficult to directly compare these values with previous literature values, because of variations in strains, media and test methods (static and continuous flow), our doubling time values (table 1) are slightly higher than those found for static culture growth of S. mutans UA140 Todd-Hewitt broth with $1 \%$ sucrose at $37^{\circ} \mathrm{C}$ at $69.4 \pm 5.1 \mathrm{~min}$ [Qi et al., 2004].

Net biofilm detachment was consistently detected after the maximum mass was achieved. To determine whether detachment is due to shear force or to processes at the molecular level, experiments were performed at lower flow rates (still in the laminar region), which would result in lower shear forces on the biofilm. Detachment consistently occurred at approximately the same time even at lower shear forces and may perhaps be a physiological phenomenon whereby surface-protein-releasing enzymes (SPRE) produced by $S$. mutans initiate detachment. In previous work, $S$. mutans biofilm became detached from hydroxyapatite rods when placed into a test tube and gently rocked, and addition of exogenous SPRE further enhanced detachment [Lee et al., 1996]. It was also found that the production of SPRE was optimal at $\mathrm{pH}$ 5-6. In the present study the $\mathrm{pH}$ in the effluent from the flow cell was measured initially and finally and found to fall from 7 to about 4 . Addition of a sensor to monitor $\mathrm{pH}$ continuously would provide additional information on the acidogenicity and aciduricity of $S$. mutans and on whether detachment corresponds to $\mathrm{pH}$ levels favorable for SPRE production.

The results shown in figure 4 suggested that an increase of $3^{\circ} \mathrm{C}$ from the optimum temperature of $37^{\circ} \mathrm{C}$ was a sufficient thermal stress on $S$. mutans UA140 to cause an increase in the lag period, most likely because of the increased proton permeability. Similar effects were found for S. mutans strain GS-5, which can grow at temperatures ranging from 32 to $45^{\circ} \mathrm{C}$, with optimal growth at $37^{\circ} \mathrm{C}$. Ma and Marquis [1997] reported that higher temperatures increased the proton permeability of $S$. $m u$ tans cells so that growth at higher temperatures may be inefficient in cells producing acid by metabolizing sugars because of increased demands for ATP to remove protons re-entering the cells.

The genetic effects on attachment ability of S. mutans were interesting. In experiments using mutants lacking the $g t f B$ and $g t f C$ genes, which are responsible for insoluble glucan synthesis, little difference in the QCM responses was detected for these mutants in comparison to the control experiment (no microbial inoculum). Lack of the $g t f B$ and $g t f C$ genes dramatically compromised the attachment and biofilm growth ability in comparison with the wild type micro-organism. The gtfB-deficient mutant did, however, show more attachment than the $g t f C$-deficient mutant by the end of the experiment. This perhaps indicated that although both water-insoluble glucans played an effect on glucan production, $g t f C$ had a greater impact on attachment ability. $g t f B$ and $g t f C$ mutants of $S$. mutans were still capable of growing planktonically as indicated by the dry weights in table 2 , but absence of $g t f B$ and $g t f C$ genes, incapacitated the ability of the biofilm to attach to a surface.

Other genes such as ciaH and luxS have also been implicated with roles in biofilm formation. The main function of $\mathrm{ciaH}$ is in the production of mutacins to deliver antimicrobial protection to the biofilm community, whereas luxS is a gene involved in cell signaling [Merritt et al., 2003; Qi et al., 2004]. Biofilm formation by mutants lacking these genes was greatly reduced, especially during the early stages of the experiment. The deletion of the luxS gene severely inhibited the ability of the bacteria to attach, indicating that cell signaling is a crucial element in biofilm attachment. The deletion of the ciaH gene affected bacterial attachment but in a different manner. Without mutacin production, the cells attached but only after a long lag period. With batch experiments, this unusual behavior could not have been detected. It is apparent from these results that the ciaH gene has functions 
related to the initial and reversible attachment processes in addition to mutacin production. Although attachment was reduced, the mutants lacking ciaH and $l u x S$ grew almost as well as the wild type.

These QCM experiments have provided real-time, in situ information on biofilm development. The results confirmed that glucan production is significant in biofilm attachment, with possibly greater contributions by water-insoluble glucans resulting from the $g t f C$ gene of
S. mutans. Since the virulence of S. mutans, an etiological agent of dental caries, is dependent on attachment, the QCM device has the potential for further investigations in the etiology and prevention of caries.

\section{Acknowledgment}

This work was supported by NIH/NIDCR grant No. 1R21DE016313.

\section{References}

Bressel A, Schulze J, Khan W, Wolfaardt G, Rohns H-P, Irmscher R, Schoning M: High resolution gravimetric, optical and electrochemical investigations of microbial biofilm formation in aqueous systems. Electrochim Acta 2003;48:3363-3372.

Davies D: Regulatory events in biofilm development; in McLean R, Decho A (eds): Molecular Ecology of Biofilms. Norwich, Horizon Scientific Press, 2002, pp 57-82.

- Dibdin GH, Shellis RP: Physical and biochemical studies of Streptococcus mutans sediments suggest new factors linking the cariogenicity of plaque with its extracellular polysaccharide content. J Dent Res 1988;67: 890-895.

-Ellen RP, Banting DW, Fillery ED: Streptococcus mutans and Lactobacillus detection in the assessment of dental root surface caries risk. J Dent Res 1985;64:1245-1249.

-Etchenique RA, Calvo EL: Gravimetric measurement in redox polymer electrodes with the EQCM beyond the Sauerbrey limit. Electrochem Commun 1999;1:167.

Flemming H: Role and levels of real-time monitoring for successful anti-fouling strategiesan overview. Water Sci Technol 2003;47:18.

Francis CA, Hector MP, Proctor GB: Precipitation of specific proteins by freeze-thawing of human saliva. Arch Oral Biol 2000;45:601606.

Hata S, Mayanagi H: Acid diffusion through extracellular polysaccharides produced by various mutants of Streptococcus mutans. Arch Oral Biol 2003;48:431-438.

- Hayacibara MF, Rosa OPS, Koo H, Torres SA, Costa B, Cury JA: Effects of fluoride and aluminum from ionomeric materials on $S$. $m u$ tans biofilm. J Dent Res 2003;82:267-271.

- Klapper I, Rupp CJ, Cargo R, Purvedorj B, Stoodley P: Viscoelastic fluid description of bacterial biofilm material properties. Biotechnol Bioeng 2002;80:289-296.

Kolenbrander PE: Oral microbial communities: biofilms, interactions, and genetic systems. Ann Rev Microbiol 2000;54:413-437.

Kreth J, Hagerman E, Tam K, Merritt J, Wong DTW, Wu BM, Myung NV, Shi W, Qi F:
Quantitative analyses of Streptococcus mu- Pearce C, Bowden GH, Evans M, Fitzsimmons tans biofilms with quartz crystal microbalance, microjet impingement and confocal microscopy. Biofilms 2004;1:277-284.

Lamont RJ, Jenkinson HF: Adhesion as an Ecological Determinant in the Oral Cavity. Norwich, Horizon Scientific Press, 2000.

Lee SF, Li YH, Bowden GH: Detachment of Streptococcus mutans biofilm cells by an endogenous enzymatic activity. Infect Immun 1996;64:1035-1038.

Li Y, Burne R: Regulation of the $g t f B C$ and $f t f$ genes of Streptococcus mutans in biofilms in response to $\mathrm{pH}$ and carbohydrate. Microbiol Rev 2001;147:2841-2848.

Loesche WJ: Role of Streptococcus mutans in human dental decay. Microbiol Rev 1986;50: 353-380.

- Lu C, Lewis O: Investigation of film-thickness determination by oscillating quartz resonators with large mass load. J Appl Phys 1972; 43:4385.

Ma Y, Marquis RE: Thermophysiology of Streptococcus mutans and related lactic-acid bacteria. Antonie van Leeuwenhoek 1997;72: 91-100.

Marsh PD, Bradshaw DJ: Dental plaque as a biofilm. J Ind Microbiol 1995;15:169-175.

Merritt J, Kreth J, Shi W, Qi F: LuxS controls bacteriocin production in streptococcus mutans through a novel regulatory component. $\mathrm{Mol}$ Microbiol 2005;57:960-969.

-Merritt J, Qi F, Goodman SD, Anderson MH, Shi $\mathrm{W}$ : Mutation of luxS affects biofilm formation in Streptococcus mutans. Infect Immun 2003;71:1972-1979.

-Nivens DE, Chambers JQ, Anderson TR, White DC: Long-term, on-line monitoring of microbial biofilms using a quartz crystal microbalance. Anal Chem 1993;65:65-69.

-Ooshima T, Matsumura M, Hoshino T, Kawabata S, Sobue S, Fujiwara T: Contributions of three glycosyltransferases to sucrose-dependent adherence of Streptococcus mutans. J Dent Res 2001;80:1672-1677.

Paster BJ, Boches SK, Galvin JL, Ericson RE, Lau CN, Levanos VA, Sahasrbudhe A, Dewhirst FE: Bacterial diversity in human subgingival plaque. J Bacteriol 2001;183:3770-3783. SP, Johnson J, Sheridan MJ, Wientzen R, Cole MF: Identification of pioneer viridans streptococci in the oral cavity of human neonates. J Med Microbiol 1995;42:67-72.

Qi F, Merritt J, Lux R, Shi W: Inactivation of the ciaH gene diminished mutacin production and competence development, altered sucrose-dependent biofilm formation, and reduced stress tolerance in Streptococcus mutans. Infect Immun 2004;72:4895-4899.

-Rodahl M, Hook F, Fredriksson C, Keller CA, Krozzer A, Przezinski P, Voinova M, Kasemo B: Simultaneous frequency and dissipation factor QCM measurements of biomolecular adsorption and cell adhesion. Faraday Discuss 1997;107:229-246.

- Sauerbrey G: Verwendung von Schwingquarzen zur Wägung dünner Schichten und zur Mikrowägung. Z Phys 1959;155:206-222.

-Socransky SS, Haffajee AD, Cugini MA, Smith C, Kent RLJ: Microbial complexes in subgingival plaque. J Clin Periodontol 1998;25: 134-144.

- Thurnheer T, Gmur R, Shapiro S, Guggenheim $B$ : Mass transport of macromolecules within an in vitro model of supragingival plaque. Appl Environ Microbiol 2003;69:17021709.

Van Houte J, Russo J, Prostak KS: Increased pHlowering ability of Streptococcus mutans cell masses associated with extracellular glucanrich matrix material and the mechanisms involved. J Dent Res 1989;68:451-459.

-White CC, Schrag L: Theoretical predictions for the mechanical response of a model quartz crystal microbalance to two viscoelastic media: a thin sample layer and surrounding bath medium. J Chem Phys 1999;111:1119211206.

- Yamashita YW, Bowen H, Burne RA, Kuramitsu HK: Role of the Streptococcus mutans gtf genes in caries induction in the specificpathogen-free rat model. Infect Immun 1993;61:3811-3817.

Yoshida A, Kuramitsu HK: Multiple Streptococcus mutans genes are involved in biofilm formation. Appl Environ Microbiol 2002;68: 6283-6291. 